\title{
Heliostat System with Wireless Closed-Loop Control
}

\begin{tabular}{|c|c|}
\hline THERMATA & 10 Thermata \\
\hline PROGRAM: & SunShot CSP R\&D 2012 \\
\hline TOPIC: & Advanced Collectors \\
\hline LOCATION: & Pasadena, California \\
\hline $\begin{array}{l}\text { AWARD } \\
\text { AMOUNT: }\end{array}$ & Up to $\$ 1.0$ million \\
\hline PROJECT TERM: & $2012-2014$ \\
\hline
\end{tabular}

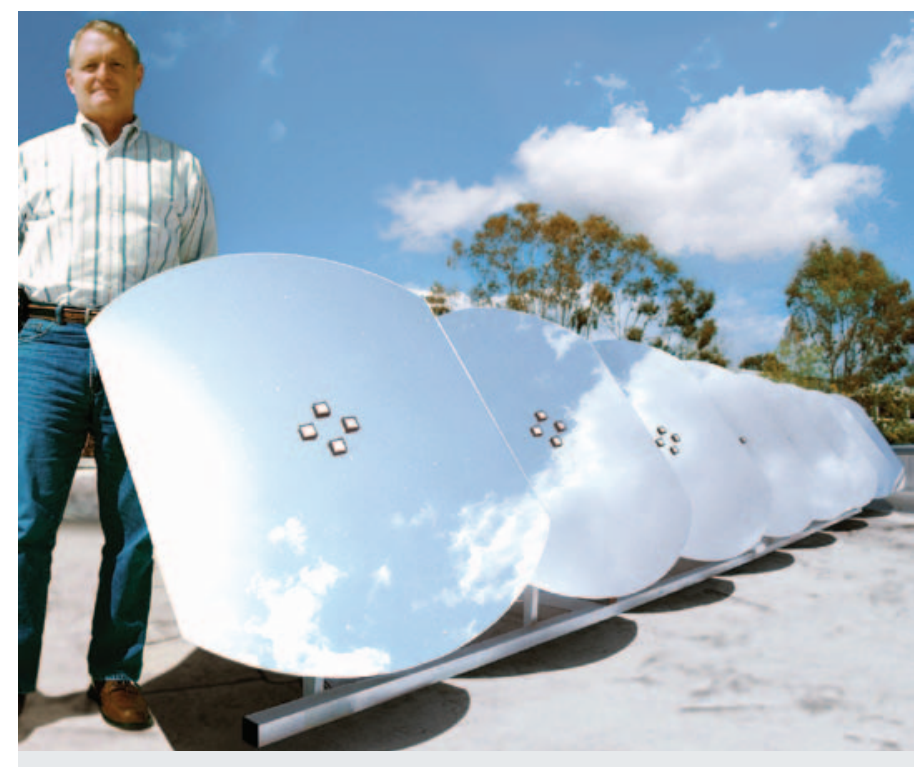

Self-powered, factory-assembled heliostats use closed-loop control to lower the cost of a solar collector field. Tower-mounted cameras sense reflections from small "solar proxies" mounted on each mirror; these reflections are then used to determine the real-time aiming point. Photo from Thermata

\section{CONTACTS}

\section{Project Leader:}

Mr. Brad Hines

Brad.Hines@thermata.com

\section{Partnering Organizations:}

- Sandia National Laboratories

- Tietronix Software, Inc.

\section{MOTIVATION}

Open-loop sun tracking requires costly precision. Traditionally, large heliostats have been the best way to amortize the costs of that precision. Open-loop tracking also requires a stable heliostat pedestal and footings, highprecision motors and frames, encoders, frequent calibration and surveying, and a fair amount of parasitic power consumption with its attendant wiring, conduits, and trenching.

\section{PROJECT DESCRIPTION}

Thermata is developing and demonstrating the first practical heliostat to use closed-loop tracking that can optically sense and control the reflected sunlight beam at the target. The researchers are also characterizing the prototype heliostat system's ability to achieve high optical efficiency and deliver thermal energy more accurately to the receiver. The closedloop tracking system eliminates expensive components like encoders, and its small size enables self-contained photovoltaic powering, eliminating wiring costs. Together, these benefits reduce the total installed cost of the heliostat field in a power tower concentrating solar power (CSP) project.

\section{IMPACT}

Using an innovative camera system and closed-loop control to accurately place the sun on any receiver target, Thermata's heliostat tracking system eliminates the need for precise, highly engineered heliostat structures. This technology enables cost reductions compared to the current state-ofthe-art technology with radically smaller, lighter-weight mirror assemblies. In addition, reduced mechanical tolerance requirements and significant reductions in both installation and operations costs are expected.

For more information, visit the project page at: www.solar.energy.gov/sunshot/csp_sunshotrnd_thermata.html. 